\title{
Cataract extraction as primary treatment for narrow angle glaucoma
}

\author{
Tania Patel*, Howell Findley and Sinda Peck
}

Alexandria Drive, Lexington, KY, USA

\begin{abstract}
Purpose: To compare the increase in anterior chamber depth (ACD) after cataract extraction/ lensectomy (CE) vs. laser peripheral iridotomy (LPI) in patients with narrow angles (NA) and narrow angle glaucoma (NAG). Effect on intraocular pressure (IOP) and cost was also evaluated.

Materials and methods: The Lenstar was used to measure ACD prior to and after cataract extraction and prior to and after LPI in patients with narrow angles. Fifty-four (54) eyes with narrow angles underwent CE and eighteen (18) eyes underwent LPI. Three (3) eyes had LPI with subsequent CE. Pre- and post-surgical IOP were also measured.

Results: The mean ACD in eyes undergoing LPI was $2.74 \mathrm{~mm}$ before and $2.81 \mathrm{~mm}$ after surgery. Mean ACD in eyes undergoing CE was $2.54 \mathrm{~mm}$ before and 4.12 $\mathrm{mm}$ after surgery. In patients undergoing LPI and subsequent CE mean ACD measured $2.65 \mathrm{~mm}$ before LPI, 2.67mm after LPI and 3.92mm after CE. Mean IOP was $21 \mathrm{mmHg}$ before LPI and $18 \mathrm{mmHg}$ after LPI. Mean IOP was $17 \mathrm{mmHg}$ before CE and $15 \mathrm{mmHg}$ after C.E.

Conclusion: Mean ACD increases significantly more after CE than LPI and should be considered as a primary treatment for patients with NAG and NA in danger of closure.
\end{abstract}

\section{Introduction}

Anatomical narrow angle is a precursor to acute and/or chronic angle closure and angle closure glaucoma. Acute angle closure is an ocular emergency that may be stabilized medically but is ultimately a surgical disease. Patients in acute angle closure (AAC) may have painful red eyes, tearing, blurred vision from corneal edema, halos around lights, circumlimbal injection, nausea, vomiting, headache, and fixed mid-dilated pupil [1]. A patient at the local Veteran's Affairs medical center described the pain from AAC to be more severe than the combination of being shot and stabbed. ACG is more common with increasing age and in females, hyperopes, Asians, East Indians, and the Inuit Eskimo population [1].

ACG is a surgical disease and has historically been treated with Laser peripheral iridoplasty (LPI). Laser iridoplasty or gonioplasty may be used as a temporary measure and lower IOP but are not considered primary standard of care. In emergency situations where IOP is severely elevated and unresponsive to medications anterior chamber paracentesis may also be performed. Trabeculoplasty may be required after failed LPI or with uncontrolled glaucoma with patent LPI [1].

\section{Materials and methods}

Patients with narrow angles were reviewed pre-and post LPI as well as pre and post cataract extraction. Van Herrick method via slit lamp examination was used initially to determine if patients had narrow angles. Gonioscopy and anterior chamber angle OCT was performed to confirm the narrowness of the angle. Patients were considered to have narrow angles if trabecular meshwork or scleral spur was not noted in any quadrant.

The Lenstar was used to measure Anterior Chamber depth (ACD) prior to and after cataract extraction (CE) and prior to and after LPI in patients with narrow angles. Fifty-four (54) eyes with narrow angles underwent CE and eighteen (18) eyes underwent LPI. Three (3) eyes had LPI with subsequent CE. Pre and post- surgical IOP were also measured.

\section{Results}

We reviewed the outcomes of 54 eyes with narrow angle that underwent CE (Table 1) and compared them to 18 similar eyes that had the traditional treatment of LPI in our office (Table 2). We also looked at 3 eyes that had LPI and later underwent CE (Table 3 ).

ACD in the $18 \mathrm{LPI}$ eyes ranged from $2.31 \mathrm{~mm}$ to $3.13 \mathrm{~mm}$ pre-LPI and from $2.39 \mathrm{~mm}$ to $3.16 \mathrm{~mm}$ post-LPI. Mean ACD was $2.74 \mathrm{~mm}$ preLPI and $2.81 \mathrm{~mm}$ post-LPI. ACD was increased $0.07 \mathrm{~mm}$ in this group. IOP ranged from $11 \mathrm{mmHg}$ to $46 \mathrm{mmHg}$ pre-LPI to 11 to $32 \mathrm{mmHg}$ post-LPI. Mean IOP was $21 \mathrm{mmHg}$ pre-LPI and $18 \mathrm{mmHg}$ post-LPI.

ACD in the $54 \mathrm{CE}$ eyes ranged from $2.16 \mathrm{~mm}$ to $3.37 \mathrm{~mm}$ pre-CE to $2.97 \mathrm{~mm}$ to $5.32 \mathrm{~mm}$ post-CE. Mean ACD was increased from 2.47 $\mathrm{mm}$ pre-CE to $4.10 \mathrm{~mm}$ post-CE. ACD was increased $1.58 \mathrm{~mm}$ in this group. IOP ranged from $10 \mathrm{mmHg}$ to $31 \mathrm{mmHg}$ pre-CE to $9 \mathrm{mmHg}$ to $23 \mathrm{mmHg}$ post-CE. Mean IOP was $17 \mathrm{mmHg}$ pre-and $15 \mathrm{mmHg}$ postCE.

Correspondence to: Tania Patel, 2353 Alexandria Drive \#260, Lexington, KY 40504, USA, Tel: (859) 224-2655; Fax: (859) 223-7147; E-mail: taniapatelod@ gmail.com

Key words: narrow angle glaucoma, clear lens extraction, angle closure glaucoma

Received: January 10, 2018; Accepted: February 06, 2018; Published: February 10 2018 
Table 1. Pre and post CE

\begin{tabular}{|c|c|c|c|c|c|}
\hline Patient No. & Eye & $\mathbf{A C D}_{\text {Before }}$ & $\mathbf{A C D}_{\text {After }}$ & IOP $_{\text {Before }}$ & $\mathbf{I O P}_{\text {After }}$ \\
\hline 66502 & OD & 3.01 & 3.06 & 16 & 20 \\
\hline 66502 & OS & 2.89 & 2.97 & 19 & 17 \\
\hline 68839 & OD & 2.6 & 4.64 & 12 & 12 \\
\hline 82176 & OS & 2.23 & 3.77 & 22 & 20 \\
\hline 77530 & OD & 2.43 & 4.1 & 11 & 14 \\
\hline 77530 & OS & 2.44 & 4.4 & 15 & 13 \\
\hline 66318 & OS & 2.67 & 3.77 & 20 & 19 \\
\hline 68438 & OD & 2.23 & 5.32 & 12 & 9 \\
\hline 68438 & OS & 2.32 & 5.08 & 10 & 10 \\
\hline 77861 & OD & 2.45 & 4.14 & 28 & 14 \\
\hline 77861 & OS & 2.25 & 5.02 & 31 & 22 \\
\hline 67943 & OD & 2.29 & 3.8 & 16 & 14 \\
\hline 67943 & OS & 2.39 & 3.7 & 17 & 14 \\
\hline 68554 & OD & 2.4 & 4.33 & 27 & 13 \\
\hline 68554 & OS & 2.36 & 4.3 & 24 & 13 \\
\hline 67381 & OD & 2.18 & 3.99 & 11 & 11 \\
\hline 13500 & OS & 2.76 & 4.62 & 14 & 12 \\
\hline 68832 & OD & 2.26 & 4.01 & 17 & 16 \\
\hline 68832 & OS & 2.36 & 3.64 & 17 & 16 \\
\hline 28047 & OD & 3.07 & 4.25 & 18 & 14 \\
\hline 28047 & OS & 3.06 & 4.72 & 19 & 17 \\
\hline 38015 & OD & 2.65 & 3.34 & 15 & 18 \\
\hline 38015 & OS & 2.74 & 2.97 & 18 & 19 \\
\hline 60462 & OD & 2.66 & 3.27 & 22 & 22 \\
\hline 60462 & OS & 2.67 & 4.03 & 21 & 22 \\
\hline 78044 & OD & 2.44 & 3.13 & 16 & 13 \\
\hline 67784 & OD & 2.27 & 4.12 & 15 & 11 \\
\hline 67784 & OS & 2.31 & 4.04 & 14 & 11 \\
\hline 80258 & OS & 2.47 & 3.96 & 15 & 13 \\
\hline 79267 & OS & 2.26 & 4.17 & 15 & 12 \\
\hline 80218 & OS & 2.16 & 4.43 & 15 & 10 \\
\hline 78868 & OS & 2.41 & 3.82 & 13 & 21 \\
\hline 78208 & OD & 2.55 & 4.37 & 14 & 10 \\
\hline 78208 & OS & 2.62 & 4.42 & 15 & 10 \\
\hline 80954 & OS & 2.41 & 4.01 & 18 & 18 \\
\hline 83731 & OD & 2.31 & 5.09 & 25 & 16 \\
\hline 82211 & OD & 2.59 & 4.2 & 14 & 15 \\
\hline 82266 & OD & 3.08 & 4.08 & 15 & 18 \\
\hline 54034 & OS & 2.5 & 4.77 & 16 & 13 \\
\hline 81565 & OD & 2.45 & 3.58 & 11 & 12 \\
\hline 66922 & OS & 2.48 & 4.47 & 24 & 16 \\
\hline 67943 & OD & 2.29 & 3.8 & 16 & 14 \\
\hline 67943 & OS & 2.39 & 3.77 & 17 & 14 \\
\hline 66791 & OD & 2.41 & 4.8 & 16 & 12 \\
\hline 66791 & OS & 2.83 & 4.17 & 16 & 12 \\
\hline 66252 & OD & 2.37 & 3.92 & 17 & 16 \\
\hline 63046 & OD & 2.82 & 5.29 & 15 & 12 \\
\hline 63046 & OS & 2.58 & 5.2 & 20 & 14 \\
\hline 67900 & OD & 2.53 & 3.41 & 10 & 11 \\
\hline 67900 & OS & 2.58 & 3.53 & 15 & 12 \\
\hline 65967 & OD & 2.48 & 3.34 & 20 & 18 \\
\hline 66628 & OD & 3.37 & 4.72 & 23 & 21 \\
\hline 66628 & OS & 3.34 & 4.5 & 23 & 23 \\
\hline 66178 & OD & 2.86 & 4.14 & 12 & 10 \\
\hline
\end{tabular}

In patients undergoing LPI and later CE, the mean ACD was $2.65 \mathrm{~mm}$ pre-LPI to $2.67 \mathrm{~mm}$ post-LPI to $3.92 \mathrm{~mm}$ post CE in the 3 eyes that underwent both procedures. IOP was $14 \mathrm{mmHg}$ pre-LPI, $17 \mathrm{mmHg}$ post-LPI and $15 \mathrm{mmHg}$ post-CE.

\section{Discussion}

Acute angle closure is an ocular emergency that may be stabilized medically but is ultimately a surgical disease. Historically, it has been treated with IOP lowering drops, LPI, or gonioplasty.

However, LPI is not always successful or without an occasional complication. Some studies show that one-third (1/3) of argon and $9 \%$ of YAG LPIs close requiring a repeat LPI. IOP is elevated higher than $21 \mathrm{mmHg}$ one to three years after LPI in $64 \%$ of eyes. Anterior lens opacities are also noted in up to $45 \%$ of eyes after LPI [2]. An article in Review of Ophthalmology reported that about $30 \%$ of eyes still have narrow or closed angles after LPI [3]. Also, some patients report bothersome streaks of light in their vision after LPI [4].

According to Adler's, the physiological lens changes thickness from $4.0 \mathrm{~mm}$ at age 20 to $4.7 \mathrm{~mm}$ at 60 years of age [5]. As it increases in thickness it pushes the iris forward resulting in a shallower anterior chamber with narrowing or occluding of the anatomical angle. An LPI may create a "by-pass" to the angle but does not significantly deepen the chamber (Figures 1 and 2). Angles may remain narrow or occluded. Exchanging a thicker physiological lens for a thinner IOL via lensectomy definitively deepens the angle, as shown by our study (Figure 3). It eliminates the need for a LPI now and cataract surgery later reducing the total number of surgeries on a given eye. It has the additional benefit of improving visual acuity and reducing ametropia.

Lately, researchers and clinicians have been investigating $\mathrm{CE}$ as a primary treatment for ACG [6]. An article by Pachimkul et. al. published in the Thai Medical Journal discussed the results of phacoemulsification in patients with acute and chronic ACG. They reported 58 eyes with a mean drop in IOP from $23.3 \mathrm{mmHg}$ pre-op to $14.8 \mathrm{mmHg}$ post-op. Improved visual acuity and lesser peripheral anterior synechiae (PAS) were also observed. They concluded CE helps reduce IOP, reduce PAS, relieve pupillary block, and increased angle depth [7]. A recent publication in Medscape by Laurie Barclay, M.D. "Clear-Lens Extraction May Be Best for Primary Glaucoma" pointed out that clear lens extraction was more effective and more cost-effective than LPI [8]. Liam et.al. reported a study of 31 patients with acute primary angle closure glaucoma who were randomized to cataract extraction by phacoemulsification vs. LPI. LPI eyes experienced higher

Table 2. Pre and Post LPI

\begin{tabular}{|c|c|c|c|c|c|}
\hline Patient No. & EYE & $\mathrm{ACD}_{\text {Before }}$ & $\mathrm{ACD}_{\text {After }}$ & $\mathrm{IOP}_{\text {Before }}$ & $\mathrm{IOP}_{\text {After }}$ \\
\hline 68100 & OD & 3.09 & 3.14 & 18 & 20 \\
\hline 68620 & OD & 3.13 & 3.04 & 46 & 20 \\
\hline 68620 & OS & 3.1 & 3.16 & 28 & 20 \\
\hline 66447 & OD & 2.5 & 2.67 & 22 & 18 \\
\hline 66447 & OS & 2.47 & 2.6 & 25 & 18 \\
\hline 77399 & OD & 2.31 & 2.39 & 18 & 16 \\
\hline 77399 & OS & 2.35 & 2.41 & 25 & 18 \\
\hline 82799 & OD & 2.85 & 2.87 & 14 & 15 \\
\hline 81857 & OS & 2.85 & 2.87 & 16 & 13 \\
\hline 82719 & OS & 2.73 & 2.77 & 13 & 18 \\
\hline 66864 & OD & 2.66 & 3 & 14 & 12 \\
\hline 66821 & OS & 2.64 & 2.78 & 17 & 19 \\
\hline 67241 & OD & 2.55 & 2.61 & 14 & 11 \\
\hline 37717 & OD & 3.01 & 3.11 & 28 & 32 \\
\hline 37717 & OS & 3.06 & 3.16 & 30 & 28 \\
\hline 59750 & OD & 2.59 & 2.6 & 21 & 17 \\
\hline 59750 & OS & 2.7 & 2.71 & 20 & 17 \\
\hline 83069 & OD & 2.69 & 2.69 & 11 & 20 \\
\hline
\end{tabular}


Table 3. Pre LPI, Post LPI and post CE

\begin{tabular}{|c|c|c|c|c|c|c|c|}
\hline Patient No. & EYE & $\mathbf{A C D}_{\text {Before LPI }}$ & ACD $_{\text {After LPI/Before CE }}$ & $\mathbf{A C D}_{\text {After CE }}$ & IOP $_{\text {Before LPI }}$ & IOP $_{\text {After LPI/Before CE }}$ & IOP $_{\text {After CE }}$ \\
\hline 29802 & OD & 2.61 & 2.64 & 3.59 & 16 & 16 & 15 \\
\hline 29802 & OS & 2.51 & 2.62 & 3.69 & 14 & 16 & 15 \\
\hline 77740 & OD & 2.82 & 2.75 & 4.48 & 13 & 18 & 16 \\
\hline
\end{tabular}

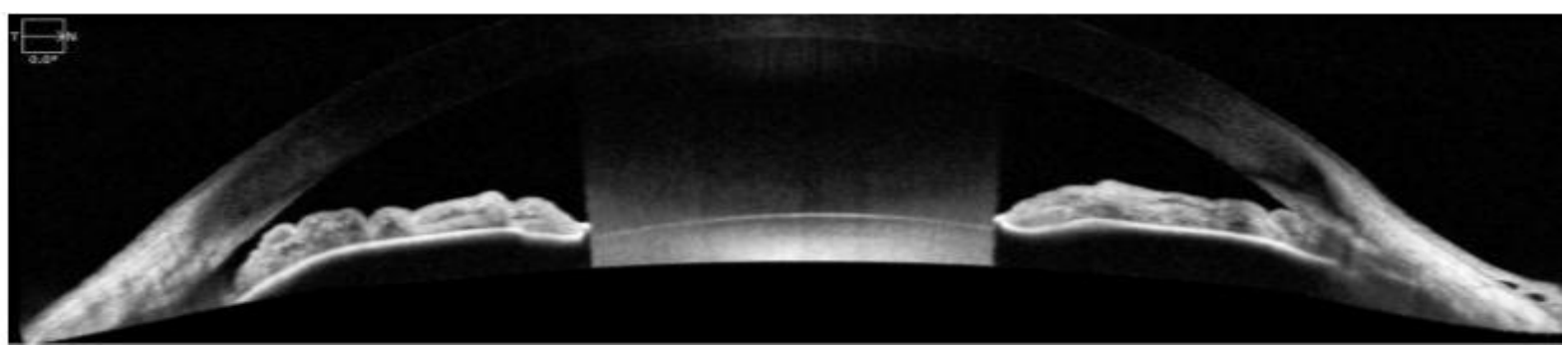

Figure 1. OCT of a narrow angle before LPI. Note PAS in the nasal angle

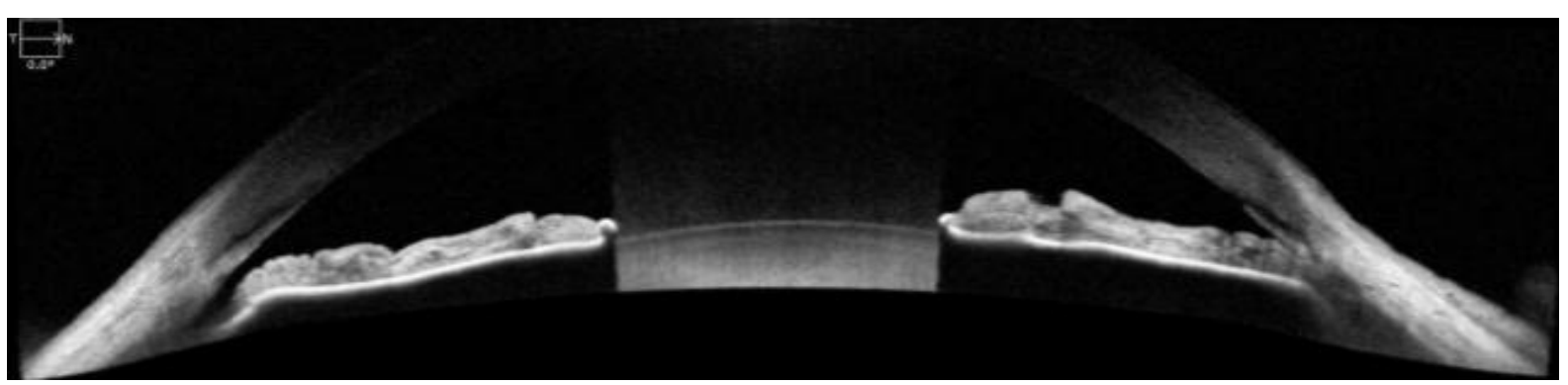

Figure 2. OCT of narrow angle after LPI. Little change in anterior chamber or angle. PAS remains.

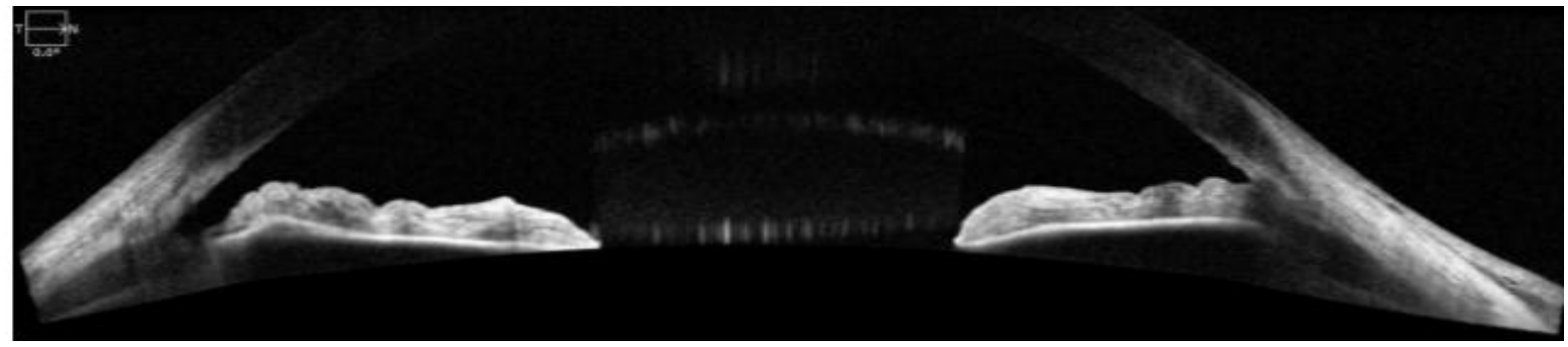

Figure 3. OCT of narrow angle after LPI and CE. Anterior chamber and angle are visibly deeper. PAS remains

IOP spikes post-op while CE eyes achieved lower IOP and deeper ACD $[9,10]$.

Looking at our results, it can be noted that there was a similar decrease in IOP with both the CE and LPI groups. Glaucoma patients that are on prostaglandin treatment are switched to either a carbonic anhydrase inhibitor (CAI) or beta blocker due to increased risk of inflammation post cataract extraction. CAI and beta blockers are known to be less effective at reducing intra ocular pressure in comparison to prostaglandin analogues. Since most of the data for IOP was measured within 1-2 months of cataract extraction, it could play a role in similar IOP decrease in both groups of patients.

Cataract surgery like every other surgery is not without risks. Removing the crystalline lens does significantly reduce the risk of angle closure glaucoma; however, there is a rare chance that a patient may suffer from malignant glaucoma due to aqueous misdirection following ocular surgery. One of the major changes to contemplate post cataract surgery is presbyopia. However, this is easily corrected with glasses or contact lenses post cataract surgery. Patients can also consider monovision with IOL implants which would provide them with good vision at distance and near. There are new advances in multifocal lenses that have shown great success with extended depth of focus. Attia et. al, published a study in the Journal of Refractive surgery in October 2017 which evaluated the extended Depth of Focus IOL. They evaluated the Tecnis Sympfony IOL by Abbott Medical Optics, Inc. They looked at 30 eyes in 15 patients and found the median uncorrected distance VA to be $0.03 \log$ MAR or Snellen 20/21.43, uncorrected near vision 0.20 $\log$ MAR or Snellen $20 / 31.70$ and uncorrected intermediate to be -0.03 logMAR or Snellen 20/18.67 [11].

Clear lens extraction or cataract surgery should be considered as first line treatment in patients with narrow angle glaucoma. Glaucoma patients are usually on medication for the rest of their lives so cost is a very important issue that should be factored into the treatment plan and discussed with patients and their families. The Effectiveness in Angle Closure Glaucoma of Lens Extraction (EAGLE) Study, which enrolled 419 participants, 155 with primary angle closure and 263 with primary angle closure glaucoma, was recently reported. Clear-lens extraction was performed on 208 and 211 had standard care of LPI. Clear-lens extraction showed greater efficacy and was more cost-effective than LPI [12]. Medicare allowable for LPI in our ASC is $\$ 394.93$ and $\$ 1406.13$ for CE. Commercial insurance allows $\$ 1,404.10$ for LPI and $\$ 1894.14$ 
for CE. This represents about a $\$ 400$ savings per eye for patients having CE rather than LPI followed by CE.

As seen in our study, greater deepening of the anterior chamber and hence the anatomical angle as well as lower IOPs were achieved with CE than were achieved with LPI in patients with NAG. Removal of the physiologic lens significantly reduces the risk of angle closure and progression of glaucoma. CE in the presence of NAG should be offered as primary treatment for this population of patients.

\section{References}

1. Glaucoma. (n.d.). In Basic and clinical science course American academy of ophthalmology pp. 120-125.

2. Laser iridotomy (n.d.) Retrieved December 6, 2016, from http://www. surgeryencyclopedia.com/La-Pa/,Laser-Iridotomy.html.

3. Kent, C. (Ed.). (2013, June 5). Managing narrow angles and glaucoma. Retrieved November 20, 2016, from https://www.reviewofophthalmology.com/article/managingnarrow-angles-and-glaucoma

4. Vera V, Naqi A, Belovay GW, Varma DK, Ahmed II (2014) Dysphotopsia after temporal versus superior laser peripheral iridotomy: A prospective randomized paired eye trial. Am J Ophthalmol 157: 929-35 [Crossref]
5. Adler FH. Physiology of the Eye, 4th ed. Mosby - Year Book: St Louis, MO, 1965; 280.

6. Moghimi S, Hashemian H, Chen R, Johari M, Mohammadi M, et al. (2016) Early phacoemulsification in patients with acute primary angle closure. J Curr Ophthalmol 27: 70-75. [Crossref]

7. Pachimkul P, Intajak Y (2008) Effect of lens extraction on primary angle closure in a Thai population. J Med Assoc Thai 91: 303-308. [Crossref]

8. Barclay L. (2016, October 7). Clear-lens extraction may be best for primary glaucoma. Retrieved November 10, 2016, from http://www.medscape.com/viewarticle/869960

9. Trikha S, Perera SA, Husain R, Aung T (2015) The role of lens extraction in the curren management of primary angle-closure glaucoma. Curr Opin Ophthalmol 26: 128-134. [Crossref]

10. Lam DS, Leung DY, Tham CC, Li FC, Kwong YY, Chiu TY, et al. (2008) Randomized trial of early phacoemulsification versus peripheral iridotomy to prevent intraocular pressure rise after acute primary angle closure. Ophthalmology 115: 1134-1140. [Crossref]

11. Attia MSA, Auffarth GU, Kretz FTA, Tandogan T, Rabsilber TM, et al. (2017) Clinical Evaluation of an Extended Depth of Focus Intraocular Lens With the Salzburg Reading Desk. J Refract Surg 33: 664-669. [Crossref]

12. Azuara-Blanco A, Burr J, Ramsay C, Cooper D, Foster PJ ,et al. (2016) Effectiveness of early lens extraction for the treatment of primary angle-closure glaucoma (EAGLE) a randomised controlled trial. The Lancet 388: 1389-1397. [Crossref]

Copyright: (C)2018 Patel T. This is an open-access article distributed under the terms of the Creative Commons Attribution License, which permits unrestricted use, distribution, and reproduction in any medium, provided the original author and source are credited. 